\title{
A CONTRIBUiÇÃo DE FILÓSOFOS JUDAICOS PARA A ÉTICA DO TRADUZIR NA CONTEMPORANEIDADE
}

\author{
The contribution of Judaic philosophers \\ to the ethics of translation
}

\author{
Maria Clara Castellões de Oliveira*
}

\begin{abstract}
RESUMO
Para fins deste trabalho, pretendo extrair dos pensamentos de Franz Rosenzweig, Walter Benjamin, Jacques Derrida e Emmanuel Lévinas, filósofos de extração judaica, percepções que contribuirão para um entendimento mais abrangente não apenas da relação entre tradução e ética na contemporaneidade como também da defesa da tradução da letra, nos termos de Antoine Berman, ou seja, da defesa da ética da diferença, endossada por estudiosos da tradução de viés pós-estruturalista.

Palavras-chave: tradução; ética; filósofos judaicos.
\end{abstract}

\begin{abstract}
For the purpose of this paper, I intend to extract from the thoughts of Jewish philosophers Franz Rosenzweig, Walter Benjamin, Jacques Derrida and Emmanuel Lévinas perceptions that will contribute to a more comprehensive understanding not only of the relation between translation and ethics in the contemporary scenery but also of the defence of the translation of the letter, in Antoine Berman's terms, in other words, of the defense of the ethics of difference, endorsed by post-structuralist translation scholars.
\end{abstract}

Keywords: translation; ethics; Jewish philosophers.

${ }^{*}$ Universidade Federal de Juiz de Fora. 
Em O Pensamento Tradutório Judaico: Franz Rosenzweig em Diálogo com Benjamin, Derrida e Haroldo de Campos, tese defendida em 2000, apontei para a existência de uma especificidade do pensamento sobre tradução erigido por intelectuais de origem judaica no contexto pós-Emancipação, ocorrida a partir do último quartel do século XVIII, quando as portas do gueto se abriram e a adaptação de muitos judeus aos costumes e valores seculares ocidentais teve início. Essa especificidade vincula-se, a exemplo da crítica pós-estruturalista de extração judaica, a uma longa tradição de interpretação das Escrituras por parte de rabinos antigos (midrashistas) e de cabalistas e a concepções não lineares de tempo e espaço, provenientes de uma história construída em entrelugares discursivos. Ela se expressa, como comprovei, através de conceitos e metáforas vinculados às exegeses bíblicas (tradução como tarefa (impossível), criação, revelação, redenção, restauração dos vasos quebrados, vestimenta e desnudamento) e a uma história marcante de diásporas (tradução como deslocamento). Uma das vozes que se fizeram mais audíveis no contexto de minhas pesquisas foi a do filósofo, teórico da tradução e tradutor Franz Rosenzweig, por mim posta em diálogo com a de outros importantes pensadores da tradução: Walter Benjamin, que lhe foi contemporâneo, e Jacques Derrida, que o sucedeu.

Ao longo de meu pós-doutoramento, realizado entre setembro de 2010 e agosto de 2011, sob a orientação de Marcio Seligmann-Silva, procurei elucidar a relação entre tradução e ética na contemporaneidade e, de certa forma, reunir justificativas para a defesa da tradução da letra, nos termos de Antoine Berman (2007 [1985]), ou seja, para a defesa da ética da diferença (BERMAN, 2002 [1984], 1995), endossada contemporaneamente por estudiosos da tradução de viés pós-estruturalista. Para tanto, procurei articular o pensamento de intelectuais de origem judaica que haviam sido alvo de pesquisas que realizei durante o meu doutoramento e o de outros judeus, como os filósofos Emmanuel Lévinas e Vilém Flusser. Este texto, portanto, traz as primeiras conclusões de minhas pesquisas recentes.

o povo judaico, embora sempre em deslocamento, viveu a maior parte de sua história confinado aos domínios do gueto. Nesse contexto, ele desenvolveu um apego excessivo aos textos bíblicos e à sua interpretação e aos estudos dos mais diversos tipos de saberes. Esse tipo de comportamento, no qual a ausência de liberdade de movimento acaba gerando um estímulo à atividade intelectual foi alvo de comentários por parte de Hannah Arendt (1906-1975) no ensaio "Sobre a Humanidade em Tempos Sombrios: Reflexões sobre Lessing” (1987 [1955]. Segundo a filósofa alemã: 
De todas as liberdades específicas que podem ocorrer em nossas mentes quando ouvimos a palavra "liberdade", a liberdade de movimento é historicamente a mais antiga e também a mais elementar. Sermos capazes de partir para onde quisermos é o sinal prototípico de sermos livres, assim como a limitação da liberdade de movimento, desde tempos imemoriais, tem sido a pré-condição da escravização. A liberdade de movimento é também a condição indispensável para a ação, e é na ação que os homens primeiramente experimentam a liberdade no mundo. Quando os homens são privados do espaço público [...] recolhem-se para sua liberdade de pensamento. Evidentemente, essa é uma experiência muito antiga (ARENDT, 1987, p. 18).

Por sua vez, Vilém Flusser (1920-1991), filósofo judeu que nasceu e faleceu em Praga e viveu no Brasil de 1940 a 1973, forneceu em Bodenlos: Uma Autobiografia Filosófica (2007) testemunho da medida em que indivíduos deslocados compartilham o que ele chamou de falta de fundamento (bodenlos, em alemão) e, também, da medida em que essa falta de fundamento interfere no modo de essas pessoas construírem suas mais diversas relações políticas, sociais e interpessoais. Segundo ele, o clima da falta de fundamento é semelhante ao das flores sem raiz; ao da movimentação sem significado dos planetas e "dos aparelhos administrativos em função dos quais passamos grande parte de nossas vidas” (FLUSSER, 2007, p. 19), tendo o nada por horizonte, e, ainda, à sensação de se estar boiando. A seu ver, "há os que se encontram na falta de fundamento [...] seja porque foram arrancados da realidade por forças externas, seja porque abandonaram espontaneamente uma situação aparentemente real, mas por eles diagnosticada como fantasmagoria" (p. 20). No entanto, qualquer que seja o motivo pelo qual certos indivíduos foram conduzidos à falta de fundamento, Flusser afirmou que eles - esses indivíduos - "existem mais intensamente, se 'existir' for interpretado como "viver por fora'” (p. 21).

Em um momento mais recente, Cynthia Ozick (1928- ), escritora, crítica literária e tradutora estadunidense, declarou que as experiências de exílio pelas quais o povo judaico passou o levou a imaginar o que significa ser o Outro; o forasteiro; o alienígena; o escravo; o oprimido; o sofredor; o proscrito; o oponente; o bárbaro que tem sentimentos e direitos (OZICK, 1996, p. 322). Em sua opinião, incitados pelas Escrituras a amarem os seus vizinhos como a si próprios e a considerarem vizinhos até mesmo aqueles que lhes eram estranhos, uma vez terem sido "estrangeiros na terra do Egito" (Levítico, 19:34), os judeus transformaram a memória concreta da escravidão em uma metáfora universalizadora da reciprocidade. Em suas palavras, "sem a metáfora da memória e da história, não podemos imaginar a vida do Outro. Não podemos imaginar o que é ser uma outra pessoa. A metáfora 
é o agente recíproco/inverso, a força universalizadora: ela torna possível a força para imaginar o coração do estranho" (OZICK, 1996, p. 325). ${ }^{1}$

Isso posto, eu diria que experiências como as dos deslocamentos que conduziram o povo judaico ao exílio e à introspecção forjaram o modo pelo qual gerações futuras ergueram sua voz na história. A possibilidade de isso ter acontecido é referendada por Jacques Derrida em Mal de Arquivo - Uma Impressão Freudiana (do francês Mal d'Archive, de 1995), publicado no Brasil em 2001. Segundo sua percepção, "sem a força e a autoridade irreprimível [...] desta memória transgeracional" (DERRIDA, 2001, p. 50), por ele considerada como "a lembrança de uma experiência ancestral ou o caráter biologicamente adquirido" (p. 49), "os problemas [...] estariam dissolvidos ou resolvidos de antemão. Não haveria mais história essencial da cultura, não haveria mais questão de memória e de arquivo, de patriarquivo ou de matriarquivo e não compreenderíamos nem mais como um ancestral pode falar de nós nem que sentido haveria para nós em falar dele [...]" (p. 50 , grifo do autor).

Os principais intelectuais de origem judaica que abordei em minha tese - Rosenzweig, Benjamin e Derrida - construíram seus pensamentos em contextos deslocados e em tempos sombrios. Rosenzweig (1886-1929) lutou na Primeira Guerra Mundial, quando começou a escrever, nas trincheiras, o livro pelo qual ficou conhecido, cujo título, em tradução literal para o português, é $A$ Estrela da Redenção (Der Stern der Erlösung) e vivenciou os desdobramentos dessa guerra, tendo, inclusive, contemplado a possibilidade de se converter ao cristianismo. Benjamin (1892-1940), por sua vez, foi marcado pela angústia dos anos imediatamente anteriores à Segunda Guerra Mundial e posteriores à sua irrupção, tendo transitado por diversos países, até vir a morrer ao tentar cruzar a fronteira da França com a Espanha. Já Derrida (1930-2004), além de ter sido submetido às restrições impostas pelo regime nazista na Argélia, vivenciou uma outra guerra, a que levou o seu país à independência da França, onde erigiu o seu pensamento e viveu a maior parte de sua vida.

Esses intelectuais reverberaram em seu pensamento sobre tradução a memória dos constantes exílios e da consequente introspecção a que seus antepassados e muitas vezes eles próprios foram submetidos ao longo da história. Não é de se estranhar, desse modo, a defesa por parte de

${ }^{1}$ Original: "Without the metaphor of memory and history, we cannot imagine the life of the Other. We cannot imagine what it is to be someone else. Metaphor is the reciprocal agent, the universalizing force: it makes possible the power to envision the stranger's heart". 
Benjamin da tradução como o resgate de um texto que, se assim não o fosse, estaria relegado ao exílio. Em "A tarefa-renúncia do tradutor" (2001[1923]), ele afirmou que "redimir, na própria a pura língua, exilada na estrangeira, liberar a língua do cativeiro da obra por meio da recriação - essa é a tarefa do tradutor" (BENJAMIN, 2001, p. 211). Devem ser lembradas também as várias referências que o mesmo faz à tradução como uma forma de deslocamento, merecendo ser citado, nesse sentido, o uso que ele faz da metáfora do círculo e da tangente para se referir à tradução como uma instância de sobrevivência do original. Segundo ele:

[...] o que resta de significativo para o sentido na relação entre tradução e original pode ser apreendido num símile: da mesma forma com que a tangente toca a circunferência de maneira fugidia e em um ponto apenas, sendo esse contato, e não o ponto, que determina a lei segundo a qual ela continua sua via reta para o infinito, a tradução toca fugazmente e apenas no ponto infinitamente pequeno do sentido do original, para perseguir, segundo a lei da fidelidade, sua própria via no interior da liberdade do movimento da língua (BENJAMIN, 2001, p. 211).

O privilégio dado por esses intelectuais à literalidade seria também, a meu ver, fruto das experiências de alteridade a que os judeus foram submetidos em seus exílios, uma vez ser esse o procedimento tradutório que permite à língua do original se fazer visível no contexto da língua da tradução, inserindo, na cena da escritura, a marca de tempos e espaços assimétricos e, por esse motivo, suscitando um diálogo entre as tradições que se infiltraram nas camadas de significação do texto original e aquelas que estão se deixando modificar. Assim, enquanto Rosenzweig defendeu a tradução literal em textos escritos sobre as traduções de poesias de Jehuda Halevi $^{2}$ e as traduções da Bíblia que realizou, alegando ser esse tipo de tradução o que se encontra disponível quando algo novo necessita ser dito (ROSENZWEIG, 1998 [1927], p. 3), Benjamin, no texto mencionado, afirmou que uma tradução transparente, que permite com que através dela a língua original seja visualizada e que, desse modo, a língua pura alcance a sua perenidade, só se torna viável através da "literalidade na transposição da sintaxe, sendo ela que justamente demonstra ser a palavra - e não a frase - o elemento originário do tradutor" (BENJAMIN, 2001, p. 209). 
A trajetória de Lévinas (1906-1995), nascido na Lituânia e radicado na França, aproxima-se de várias maneiras das de Rosenzweig, Benjamin e Derrida, pois ele foi indelevelmente marcado pelos atos de que foi vítima e que testemunhou no período da última grande guerra e pelo descortinamento das reais proporções do Holocausto (ou da Shoah, termo que vem sendo utilizado com mais frequência pelos que abordam esse evento no âmbito dos estudos culturais).

A articulação de seus pensamentos aos dos intelectuais que mencionei anteriormente é respaldada por Susan Handelman em vários trechos de Fragments of Redemption: Jewish Thought and Literary Theory in Benjamin, Scholem, and Levinas (literalmente Fragmentos de redenção: pensamento judaico e Teoria Literária em Benjamin, Scholem e Lévinas), livro publicado em 1991. Segundo ela, "como Benjamin e Rosenzweig, Lévinas propõe um assalto a todos os idealismos filosóficos e à dialética hegeliana que reivindica circunscrever o Todo no pensamento" (HANDELMAN, 1991, p. 181). ${ }^{3}$ Em sua concepção, "o grande ataque de Lévinas à 'totalidade' em Hegel, em Heidegger e na fenomenologia, encontrado em Totalidade e Infinito, e a inversão da consciência de e para si mesmo na ética do para o outro, tem uma [...] forte influência: a obra de Franz Rosenzweig" (HANDELMAN, 1991, p. 182). ${ }^{4}$ A autora valeu-se de estudos realizados por Richard Cohen para enfatizar ter sido "uma leitura de Rosenzweig em 1935 que possibilitou a Lévinas criticar a ontologia de Heidegger como um movimento totalizante que exclui a alteridade, e, mais tarde, desenvolver a noção da filosofia como ética" (p. 185). ${ }^{5}$

Além disso, nas palavras de Handelman,

existe uma linha clara que se estende da crítica de Rosenzweig ao pensamento hegeliano [...] até a crítica de Lévinas à totalidade e, também, até a sua concepção da linguagem, do rosto, da alteridade, do messianismo, da escatologia, da história e da relação entre o pensamento judaico e não-judaico - e que se prolonga de Lévinas até a crítica de Derrida à metafísica ocidental (HANDELMAN, 1991, p. 185). ${ }^{6}$

${ }^{3}$ Original: "Like Benjamin and Rosenzweig, Levinas proposes an assault on all philosophical idealisms and Hegelian dialectics which claim to encompass the All in thought". Essa e as demais citações de Handelman (1991) foram traduzidas por mim do original em inglês.

${ }^{4}$ Original: "[...] role in shaping modern philosophy is still underacknowledged".

${ }^{5}$ Original: "[...] a reading of Rosenzweig in 1935 that then enables Levinas to critique Heidegger's ontology as another totalizing movement which forecloses alterity, and to then develop the notion of philosophy as ethics".

${ }^{6}$ Original: "[...] there is a clear line from Rosenzweig's critique of Hegelian thought in The Star to Levina's critique of totality and also to his conceptions of language, the face, alterity, messianism, eschatology, history, and the relation of Jewish to non-Jewish thought - and from Levinas on to Derrida's critique of Western metaphysics". 
Apesar do reconhecimento por parte de Derrida de que, ao contrário do defendido por Lévinas, "a linguagem é sempre violência e não pode servir como um domínio puro da ética e da não-violência" (HANDELMAN, 1991, p. 228), ${ }^{7}$ o trabalho de ambos é, na percepção de Handelman, "uma duplicação híbrida não-categorizável, algumas vezes dissonante" (HANDELMAN, 1991, p. 271). ${ }^{8}$ Para essa autora, enquanto Derrida "tornou possível uma apreciação renovada de Lévinas" (HANDELMAN, 1991, p. 179), ${ }^{9}$ este foi "um dos pensadores que tornaram Derrida e a desconstrução possível” (p. 179). ${ }^{10}$

Embora Lévinas não tenha contemplado especificamente a questão da tradução em sua filosofia, acredito ser possível entrelaçar seu pensamento sobre ética à forma como essa atividade foi pensada por Rosenzweig, Benjamin e Derrida e é defendida na contemporaneidade por intelectuais que se filiam ao pensamento pós-estruturalista.

Um dos principais aspectos que caracterizam a filosofia de Lévinas - se não o principal - é o seu distanciamento da filosofia ocidental clássi$\mathrm{ca}$, de raízes gregas. Enquanto essa filosofia transformou o sujeito em um princípio supremo, em função de "seu enfoque demasiadamente centrado no eu que totaliza nele o Mesmo e o Outro" (CARRARA, 2010, p. 21), segundo percepção de Ozanan Vicente Carrara, autor de Lévinas: Do Sujeito Ético ao Sujeito Político - Elementos para Pensar a Política Outramente (2010), Lévinas defendeu a pluralidade da subjetividade, que "deverá ser capaz de manter separados o Mesmo e o Outro, de modo que o Mesmo não seja o outro do outro e o outro o mesmo que si" (CARRARA, 2010, p. 13). Para ele, é ao responder ao apelo do Outro - uma força ética - que eu me constituo enquanto sujeito.

Em Totalidade e Infinito (2008 [1980]), Lévinas diz chamar-se

ética a esta impugnação da minha espontaneidade pela presença de Outrem. A estranheza de Outrem - a sua irredutibilidade a Mim, aos meus pensamentos e às minhas posses - realiza-se precisamente como um pôr em questão da minha espontaneidade, como ética (LÉVINAS, 2008, p. 30).

\footnotetext{
${ }^{7}$ Original: "[...] language is always violence".

${ }^{8}$ Original: "[...] is an uncategorizable hybrid, a sometimes dissonant doubling".

${ }^{9}$ Original: "[...] made possible a renewed appreciation of Levinas".

${ }^{10}$ Original: "[...] one of the thinkers who made Derrida and deconstruction possible".
} 
Para esse filósofo, o atendimento às demandas daquele que se faz diferente de Mim é capaz de romper a totalidade e instaurar a alteridade, desconsiderada pela filosofia ontológica ocidental, cuja preocupação precípua foi a de suprimir a multiplicidade, reduzir a estranheza contida no Outro aos valores do Mesmo. Esse tipo de redução, do Outro ao Mesmo, embala a lógica da fraternidade, um sentimento que só existe entre os iguais. A ética de Lévinas pauta-se nas relações de amizade, onde os membros dessa relação mantêm suas identidades. Segundo Carrara, no livro mencionado:

\begin{abstract}
O amigo em Lévinas não é aquele que se parece comigo, mas justamente aquele que é diferente. Não posso nem escolher meu próximo, pois ele é o primeiro visto ou o primeiro que se coloca no meu caminho. Trata-se então de se colocar em relação com aquele que é diferente, com o desconhecido. A alteridade de outrem consiste justamente não em partilhar algo que ele tem em comum comigo ou vice-versa, mas ela consiste numa irredutibilidade àquilo que eu posso determinar. Outrem se caracteriza justamente por tudo que escapa ao meu controle, pelo que é dessemelhante ou diferente. É nesse sentido que a relação ética é assimétrica. Não há nada comum entre o Mesmo e o Outro. Isso é impensável para Aristóteles (CARRARA, 2010, p. 93).
\end{abstract}

Da mesma forma como "a relação ética é assimétrica", assim também - digo eu - o é a tradução, exemplo quintessencial de encontro do Mesmo com o Outro. Nesse encontro, de acordo com a mesma lógica que embala o pensamento levinasiano - e eu diria, em função dessa lógica - o Mesmo e o Outro estabelecem uma relação dialógica, tentando dar conta de um desejo que, segundo Lévinas, jamais será plenamente satisfeito. Para Lévinas, o desejo que une o Outro a Mim é o desejo metafísico, que

não aspira ao retorno, porque é desejo de uma terra onde de modo nenhum nascemos. De uma terra estranha a toda a natureza, que não foi nossa pátria e para onde nunca iremos. O desejo metafísico não assenta em nenhum parentesco prévio; é desejo que não poderemos satisfazer (LÉVINAS, 2008, p. 20).

Esse tipo de percepção se fez presente no discurso de Derrida ([1985] 2002) acerca de "A Tarefa-Renúncia do Tradutor". Para ele, é em atendimento a uma inevitabilidade que o homem traduz e é por essa mesma inevitabilidade que a tarefa do tradutor carrega consigo a marca da 
impossibilidade, uma vez que se constitui na tentativa de pagamento de uma dívida insolvente.

Sem o propósito de fechar questão em torno da possibilidade de articulação do pensamento de Lévinas sobre ética, do entendimento da tradução e da defesa da ética da diferença na contemporaneidade, eu diria, ainda, que a ideia da tradução como uma tarefa, que, além de se fazer presente no texto de Benjamin já percorrera o discurso de Rosenzweig acerca da tradução de poemas e hinos de Jehuda Halevi para o alemão (OLIVEIRA, 2000, p. 85), aponta para o elo de responsabilidade que existe entre Mim e o Outro, constituindo-se, pois, nos termos de Lévinas, uma situação ética.

A maneira de dar conta dessa responsabilidade linguisticamente foi, de certa forma, sinalizada por Lévinas em Autrement qu'Être ou au-delà de l'Essence (traduzido em Portugal com o título de De Outro Modo que Ser ou para lá da Essência). Segundo Carrara, para Lévinas,

o Outro terá de ser dito na linguagem do Mesmo, sem no entanto se reduzir ao dito. O Dizer será sempre o excesso do dito onde o Outro se deixa ver. O nascimento latente do sujeito se dá no Dizer que é a pura exposição do sujeito, mas esta anarquia pré-original exige um discurso que, embora a traia, é capaz de dizê-la ou de deixá-la manifestar-se a uma consciência (CARRARA, 2010, p. 60).

Antes de finalizar, gostaria de dizer que compartilho a percepção da possibilidade de entrelaçar o pensamento de Lévinas sobre ética e tradução com Marcio Seligmann-Silva. No ensaio "Globalização, Tradução e Memória”, integrante do livro O Local da Diferença: Ensaios sobre Memória, Arte, Literatura e Tradução (2005), o referido intelectual defendeu, a partir da leitura de Autrement qu'Être ou au delà de l'Essence, de 1974, e Le Temps et l'Autre (O Tempo e o Outro), de 1991, obras escritas por Lévinas, uma ética dialógica da tradução. Em seu ensaio, Seligmann-Silva chamou atenção para o papel fundamental da Shoah "no desenho dessa ética da tradução baseada no diálogo e no respeito" (SELIGMANN-SILVA, 2005, p. 210). De minha parte, procurei, com este texto, apontar para o fato de que, no contexto do pensamento erigido por intelectuais de extração judaica, mesmo antes da Shoah o paradigma tradicional da representação já sofrera um abalo (SELIGMANN-SILVA, 2005, p. 211), em função da longa história de deslocamentos e exílios a que o povo judaico foi submetido.

Considero também necessário esclarecer que, embora não tenha feito neste texto qualquer menção ao pensamento de Antoine Berman acer- 
ca da tradução da letra, que para ele não é "nem calco, nem (problemática) reprodução, mas atenção voltada para o jogo dos significantes" (BERMAN, 2007, p. 16), e da defesa da ética da diferença, aquela que, a meu ver, "não apaga as marcas da sua origem e coloca em xeque a estabilidade da crença na existência da superioridade de um texto sobre outro, de uma língua sobre outra, de uma literatura sobre outra, de uma cultura sobre outra" (OLIVEIRA, 2006, p. 1), acredito ter contribuído para a percepção da existência de uma relação entre esse tipo de tradução e esse tipo de ética e o pensamento dos intelectuais judaicos aqui mencionados.

\section{REFERÊNCIAS}

ARENDT, Hannah. Sobre a humanidade em tempos sombrios - reflexões sobre Lessing. In: . Homens em tempos sombrios. 2. ed. Tradução: Denise Bottmann. São Paulo: Companhia das Letras, 1987 [1955]. p. 13-36.

BENJAMIN, Walter. A tarefa-renúncia do tradutor. Tradução: Susana Kampff Lages. In: HEIDERMANN, Werner (Org.). Clássicos da teoria da tradução. Florianópolis: UFSC 2001. p. $188-215$.

BERMAN, Antoine. A prova do estrangeiro: cultura e tradução na Alemanha romântica - Herder, Goethe, Schlegel, Novalis, Humboldt, Schleiermacher, Hölderlin. Tradução: Maria Emília Pereira Chanut. Bauru: EDUSC, 2002 [1984].

. A tradução e a letra ou o albergue do longinquo. Tradução: Marie-Hélène Catherine Torres $e t$ al. Rio de Janeiro: 7 Letras/PGET, 2007 [1985].

. Pour une critique des traductions: John Donne. Paris: Gallimard, 1995.

CARRARA, Ozanan Vicente. Lévinas: do sujeito ético ao sujeito político elementos - para pensar a política outramente. Aparecida: Idéias\&Letras, 2010.

DERRIDA, Jacques. Mal de arquivo: uma impressão freudiana. Tradução: Cláudia de Moraes Rego. Rio de Janeiro: Relume Dumará, 2001 [1995].

. Torres de Babel. Tradução: Junia Barreto. Belo Horizonte: UFMG, 2002.

FLUSSER, Vilém. Bodenlos: uma autobiografia filosófica. Tradução: Gustavo Bernardo. São Paulo: Annablume, 2007.

HANDELMAN, Susan A. Fragments of Redemption: Jewish Thought \& Literary Theory in Benjamin, Scholem \& Levinas. Bloomington: Indiana University Press, 1991.

LÉVINAS, Emmanuel. Totalidade e infinito. Tradução: José Pinto Ribeiro. Revisão: Artur Morão. Lisboa: Edições 79, 2008 [1980].

OLIVEIRA Maria Clara Castellões de. Escritores brasileiros e a ética da tradução: o caso de Érico Verissimo In: CONGRESSO INTERNACIONAL DA ABRALIC, 10., 2006, Rio de Janeiro. Anais... Rio de Janeiro: UERJ, 2006. p. 1-9.

.o pensamento tradutório judaico: Franz Rosenzweig em diálogo com Benjamin, Derrida e Haroldo de Campos. Tese (Doutorado Estudos Literários) - Faculdade dde Letras, UFMG, Belo Horizonte, 2000. 
OzICK, Cynthia. Metaphor and memory. In: . Portrait of the Artist as a Bad Character and other Essays on Writing. London: Pimlico, 1996. p. 311-329.

ROSENZWEIG, Franz. Observações sobre os hinos e poemas de Jehuda Halevi (1922/23). Tradução: Marie-Anne Kremer. [s.l.]:[s.n.], 1998 [1927]. (Mimeogr.)

SELIGMANN-SILVA, Márcio. Globalização, tradução e memória. In: O local da diferença: ensaios sobre memória, arte, literatura e tradução. São Paulo: Editora 34, 2005. p. 205-213.

Submetido em: 22/04/2012

Aceito em: 09/07/2012 